\title{
Comparing the Effects of Atorvastatin on LDL Reduction through Systematic Review Method and Meta-Analysis
}

\author{
Samiramiss Qavam ${ }^{1}$, Masoumeh Shohani ${ }^{2}$, Firoz Balavandi ${ }^{1}$, Ramak Qavam ${ }^{3} \&$ Hamed Tavan ${ }^{2}$ \\ ${ }^{1}$ Department of Cardiology, Hospital of Shahid Mostafa Khomeini, Ilam University of Medical Sciences, Ilam, \\ Iran \\ ${ }^{2}$ Nurse, Faculty of Nursing and Midwifery, Psychosocial Injuries Research Center, Ilam University of Medical \\ Sciences, Ilam, Iran \\ ${ }^{3}$ Colorectal Research Center, GI fellow, Rasoul-e-Akram Hospital, Iran University of Medical Sciences, Tehran, \\ Iran
}

Correspondence: Hamed Tavan, Iran, Ilam University of Medical sciences, Faculty of Nursing and Midwifery, PO Box: 69391-77143, Ilam, Iran. Tel: 98-841-222-7123; Fax: 98-841-222-7134. E-mail: hamedtavan@gmail.com

Received: June 27, 2016 Accepted: September 5, 2016 Online Published: October 28, 2016

doi:10.5539/gjhs.v9n5p253 URL: http://dx.doi.org/10.5539/gjhs.v9n5p253

\begin{abstract}
Background and Goal: LDL is one of the important risk factors that cause cardiovascular diseases. Improving one's lifestyle accompanied by taking medicine can be effective in reducing the amount of LDL. This study aims at comparing the effects of Atorvastatin on reducing LDL using systematic review method and meta-analysis.

Materials and Methods: In this systematic review, Pub Med, Scopus, Elsevier and Google Scholar search engine were applied to do a search within the time span of 2003-2014 using standard key words. Articles which met the entrance criteria were studied. Random effects model was used to integrate the results through meta-analysis. Data were analyzed using Stata software (version 11.1).

Findings: In a systematic review, 11 articles were passed through the process of meta-analysis with a sample size of 3662 individuals and a mean of 333 subjects per study. The rate of LDL reduction was 33.32 milligrams per Deciliter by Atorvastatin. The meta-regression graph based on age showed that in the studies where the age of the sample has been younger, the amount of LDL has been higher and in studies with older sample age, the LDL rate has been lower. The meta-regression graph to BMI showed that people with higher BMI, showed more reduction in LDL and individuals with lower BMI, indicated less LDL reduction.
\end{abstract}

Conclusion: According to the results of the study, LDL reduction takes place better and more quickly in the elderly and fat individuals. Atorvastatin was more effective in reducing the rate of LDL.

Keywords: Atorvastatin, LDL, meta-analysis, systematic review

\section{Introduction}

Among the cardiovascular diseases, Coronary Artery Disease (CAD) is the major cause of death or disability. Medicinal methods, interventional procedures and surgery are used to treat CAD (Di Angelantonio, 2010; Genser, 2008). One of the methods used in recent years to reduce myocardial necrosis while carrying out PCI, has been the use of Statin medicines especially Atorvastatin and Rosuvastatin (Higgins, 2011; Begg \& Mazumdar, 1994). Some trial studies showed that using Atorvastatin reduces the rate of myocardial infarction, MI around non-emergency PCI operations (Egger et al., 1997; Anagnostis et al., 2011). In addition, a few studies showed that using a high dose of Atorvastatin such as a single $80 \mathrm{mg}$ dose or Rosuvastatin such as a single $40 \mathrm{mg}$ dose one day before PCI would reduce the rate of infarction around PCI (Ferdinand et al., 2006; Milionis et al., 2006).

Other studies showed that the rate of LDL is related to the risk of myocardial infarction atherosclerosis and if we can reduce the amount of LDL, we would be able to decrease the risk posed by those diseases. Healthy diet, doing exercise and mild physical activities are some of the ways that can prevent LDL increase (Brunetti, 2007; Stalenhoef, 2005). Studies indicate that Atorvastatin and Rosuvastatin reduce LDL but there are not any meta-analytical studies that can tell us exactly what dose of Atorvastatin or Rosuvastatin would reduce how many milligrams of the initial LDL and what dose of the medicines (Atorvastatin $40 \mathrm{mg}$ or $80 \mathrm{mg}$, Rosuvastatin $40 \mathrm{mg}$ or 
$20 \mathrm{mg}$ ) would reduce what amount of body fat. Since numerous studies have been conducted about the effects of Atorvastatin and Rosuvastatin on LDL reduction and in order to validate the results of those studies, it seems necessary to carry out a meta-analysis so that precise and valid doses are provided for planners and researchers in this field. The aim of this study is to determine and compare the amounts of LDL reduction caused by Atorvastatin and specify those amounts according to geographical region, patients' age, year of study, sex and risk factors through meta-analysis.

\section{Materials and Methods}

This study is a systematic review which adopts a meta-analysis method. The data for this study are extracted from articles published in PubMed, Scopus, Elsevier and Google Scholar. Valid key words such as "meta-analysis", "Rosuvastatin", "Atorvastatin" and "reduction of LDL" and their possible combinations were searched using AND and OR operators.

\subsection{Selection of Studies and Data Mining}

First, the researchers collected all articles related to the effect of Atorvastatin on LDL reduction and after that prepared a list of article abstracts. So, all papers in whose titles the phrases "effect of Atorvastatin and LDL reduction" appeared were put on the list and other studies which discussed Atherosclerosis treatment through surgery and risk factors that increase LDL were set aside. In the next step, a checklist of the essential data for the study (researcher's name, article title, year, place, number of subjects in the sample, number of male subjects, number of female subjects, effects of Atorvastatin on LDL reduction among men (before treatment and after treatment), effects of Atorvastatin on LDL reduction among women (before treatment and after treatment), amount of LDL reduction based on time, amount of LDL reduction based on sample size, place of conducting the study shown by a code, age group, LDL risk factors and their subcategories which had been initially assessed were used for final evaluation. Finally, the researchers examined the eventual checklist and the articles related to the study entered the meta-analysis phase. In the primary search, 60 papers were made accessible using standard key words and 30 of them which had relevant topics were put on the list of article abstracts. Eventually, the articles were qualitatively assessed using a checklist of parameters including sample size, time of conducting research, effect of Atorvastatin on LDL reduction (before and after treatment), in male and female subjects. Papers which studied the rate of LDL reduction (before and after treatment), due to Atorvastatin use went through final confirmation. In the end, nine appropriate articles entered the process of meta-analysis. The whole texts of the articles were reviewed during analysis.

\subsection{Statistical Analyses}

Since the effect of Atorvastatin on the rate of LDL (before treatment and after treatment) and sample size had been extracted from each article, binomial distribution was used to calculate the variance of each study. To blend different rates of LDL reduction, weighted average was used. A weight was given to each study proportionate to its inverse variance. Due to great differences in LDL reductions in different studies (i.e. heterogeneity of the studies) and significance of the heterogeneity index $\left(\mathrm{I}^{2}\right)$, random effects model was used in the meta-analysis. The rate of heterogeneity in this study was $98.141 \%$ which puts it in the category of studies with severe heterogeneity (Low heterogeneity is when $\mathrm{I}^{2}$ index is smaller than $25 \%$, it is medium when the index is between $25 \%$ and $75 \%$ and high when the index is above $75 \%$ ).

Meta-regression analysis was used to compare the effects of Atorvastatin on LDL reduction taking into account the year in which the study was conducted and investigating the reason for which the results became heterogeneous. The effects of Atorvastatin on LDL reduction among male and female subjects (before treatment and after that) were studied considering LDL reduction based on time, sample size, age group and year of the study through the analysis of subcategories. Data were analyzed using STATA software (version 11.1).

\section{Findings}

In a systematic review of 60 articles, abstracts of 30 papers were selected after investigating the topics and different aspects to be studied were extracted from the abstract and put on the checklists. After the final analysis, 11 papers were checked and passed through the checklist and the researcher gained access to the full texts of the articles (Figure 1: the study's flowchart).

The eventual investigations were completed between 2003 and 2014. The total sample size was 3662 people with a mean of 333 individuals in each study. Globally, six studies were conducted in Asia (54.54\%) in the countries of South Korea, Japan and China, three studies (27.27\%) were carried out in Europe in the countries of Finland, Greece and Italy, one study was performed in America (9.09\%) and one study was conducted in Africa (9.09\%). 
Sampling method in all these studies was in the form of listing the researches that met the criteria of entrance. These criteria included reporting the rate of LDL (Milligrams in Deciliter) before and after therapy and estimating the effects of Atorvastatin on LDL reduction. The least amount of LDL reduction by Atorvastatin was reported in Keith (2006) in Africa which was 31.8 milligrams per deciliter and the highest amount was reported in Anagnostis (2011) in Greecewhich showed 82 milligrams per deciliter reduction in LDL. The information about the articles investigating the effect of Atorvastatin on the rate of LDL reduction is shown in Table 1.

Due to heterogeneity of the studies $\left(\mathrm{I}^{2}\right.$ index $=98.48 \%$ ), confidence intervals for each study and for all studies based on the random effects model are shown in graph 1 A) Forest plot for the effect of Atorvastatin on LDL reduction before treatment .

Graph 2 A) is the forest plot for the effect of Atorouvastatin on LDL reduction before treatment. The initial LDL reduction rate using Atorvastatin was 42.098 milligrams per deciliter with the significance level of $\mathrm{P}=0.000$ and $\mathrm{I}^{2}$ index was $98.141 \%$. LDL reduction rate was 33.23 milligrams per deciliter with the significance level of $\mathrm{P}=0.000$ and $\mathrm{I}^{2}$ index of $98.489 \%$. High $\mathrm{I}^{2}$ index shows that the results of the studies are drastically different from one another and low $\mathrm{I}^{2}$ indicates that the results are significantly similar.

Meta-regression graph of the studies based on age, shows that in the studies where the sample's age were young, the rate of LDL was high and in the studies where the sample's age was older, LDL had a lower amount (graph 3).

Meta-regression graph of the studies based on BMI shows that individuals who had higher BMIs, their LDL was reduced more and people who had smaller BMIs, showed less LDL reduction. It means that the higher the weight, the more LDL would be reduced through Atorvastatin consumption (graph 4).

Publication bias obtained through the results is shown in graph 5 and indicates that in this type of studies, bias has not had any effect. It is shown in the form of symmetry in a funnel-shaped graph. The sizes of circles show the weights of the studies (Greater circles have more subjects in their samples and the smaller circles have less subjects).

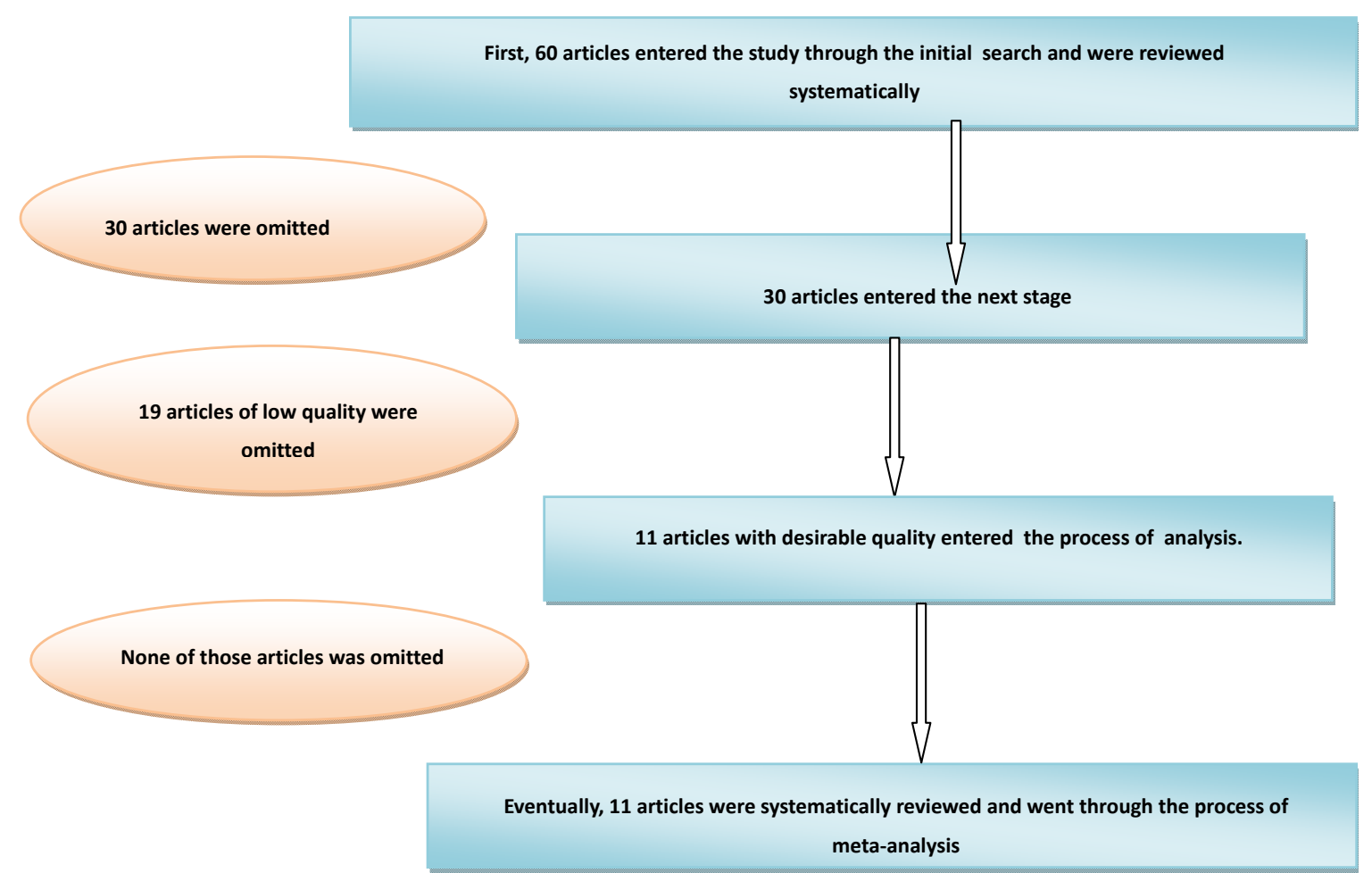

Figure 1. Flowchart of the stages that studies go through to enter the processes of systematic review and meta-analysis 
Table 1. Characteristics of the articles under investigation related to the effect of Atorvastatin on LDL reduction in $\mathrm{Mg} / \mathrm{dl}$

\begin{tabular}{lllllllll}
\hline $\begin{array}{l}\text { Change } \\
\text { LDL }(\mathrm{Mg} / \mathrm{dl})\end{array}$ & $\begin{array}{l}\text { LDL(after } \\
\text { treatment) }\end{array}$ & LDL(initial) & Male(N) & Female(N) & Numbers & Year & City & Aoutor \\
\hline $42.5 \mathrm{Mg} / \mathrm{dl}$ & 218.5 & 261 & 100 & 65 & 165 & 2005 & Fanland & Anton 11 \\
$50.4 \mathrm{Mg} / \mathrm{dl}$ & 237.6 & 288 & 80 & 107 & 187 & 2003 & USA & Evan 12 \\
$31.8 \mathrm{Mg} / \mathrm{dl}$ & 157.3 & 189.1 & 133 & 250 & 383 & 2006 & Africa & Keith13 \\
$47 \mathrm{Mg} / \mathrm{dl}$ & 70 & 117 & 63 & 17 & 80 & 2011 & $\begin{array}{l}\text { South } \\
\text { Korea }\end{array}$ & Young 14 \\
$69 \mathrm{Mg} / \mathrm{dl}$ & 93 & 162 & 34 & 65 & 99 & 2011 & Japan & Keifro 15 \\
$51.78 \mathrm{Mg} / \mathrm{dl}$ & 91.48 & 142.26 & 34 & 20 & 54 & 2009 & China & Haiyan 16 \\
$3.9 \mathrm{Mg} / \mathrm{dl}$ & 95.2 & 99.1 & 11 & 5 & 16 & 2007 & Italy & 17 Natale \\
$65.48 \mathrm{Mg} / \mathrm{dl}$ & 98.37 & 163.85 & 67 & 111 & 178 & 2010 & $\begin{array}{l}\text { South } \\
\text { Korea }\end{array}$ & joun-seon \\
$54 \mathrm{Mg} / \mathrm{dl}$ & 75 & 129 & 21 & 7 & 28 & 2012 & Japan & $\begin{array}{l}\text { Kensa } \\
\text { ke }\end{array}$ \\
- & - & 149 & 618 & 187 & 805 & 2014 & China & 20 yankle \\
$82 \mathrm{Mg} / \mathrm{dl}$ & 110 & 192 & 10 & 42 & 52 & 2011 & Greece & $\begin{array}{l}\text { Anagnostis } \\
\end{array}$ \\
\hline
\end{tabular}

Numbers indicate the reference numbers in the text.

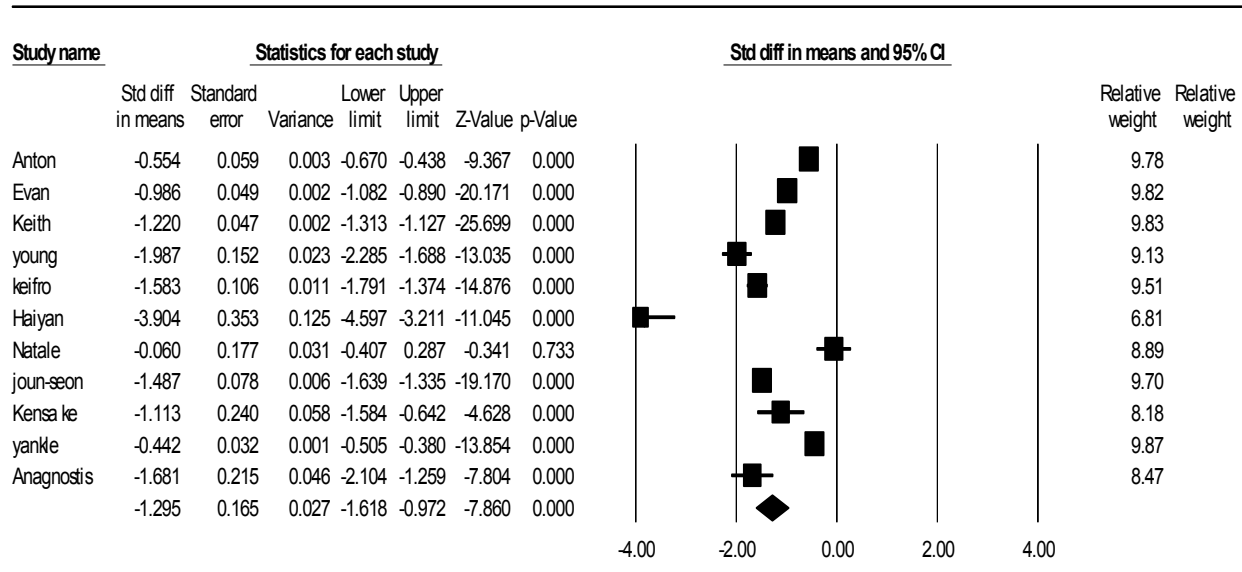

\section{Forest plot for the effect of Atorvastatin on LDL reduction before treatment with the confidence interval of} $95 \%$

Graph 1. Effect of Atorvastatin on LDL reduction before treatment with the confidence interval of $95 \%$ generally and separately for all studies according to random effects model, segments show the confidence interval for amount of LDL reduction in each study. The middle point in each segment is an estimation of the amount of LDL reduction in each study. The diamond shows the confidence interval for the amount of LDL reduction for all the studies 


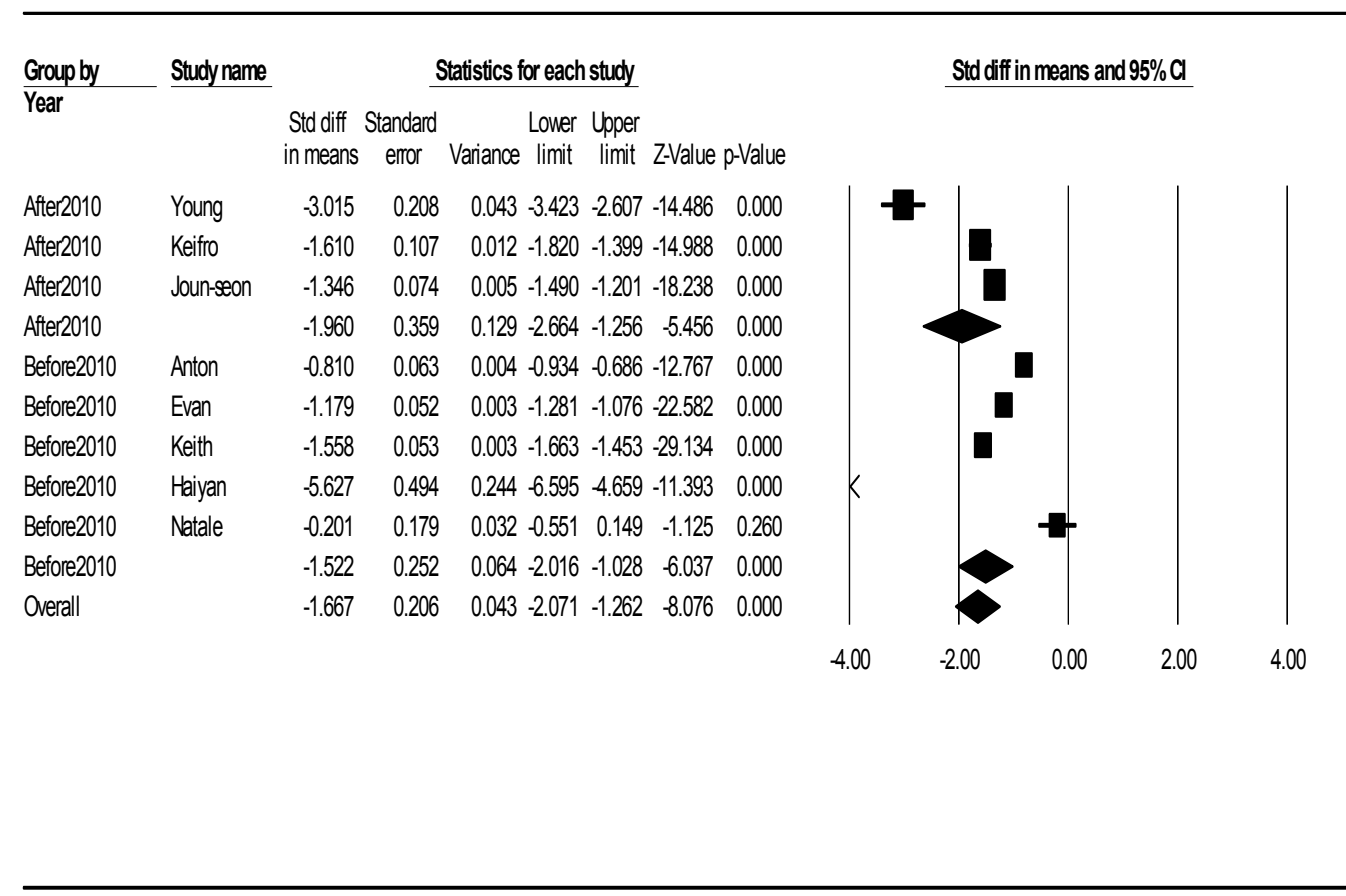

Forest plot for the effect of Atrovastatin on LDL reduction after treatment with the confidence interval of $95 \%$ Graph 2. The amount of Atrovastatin effect on LDL reduction after treatment with the confidence interval of $95 \%$ generally and separately for all studies based on the random effects model, segments show the confidence interval for amount of LDL reduction in each study. The middle point in each segment is an estimation of the amount of LDL reduction in each study. The diamond shows the confidence interval for the amount of LDL reduction for all the studies

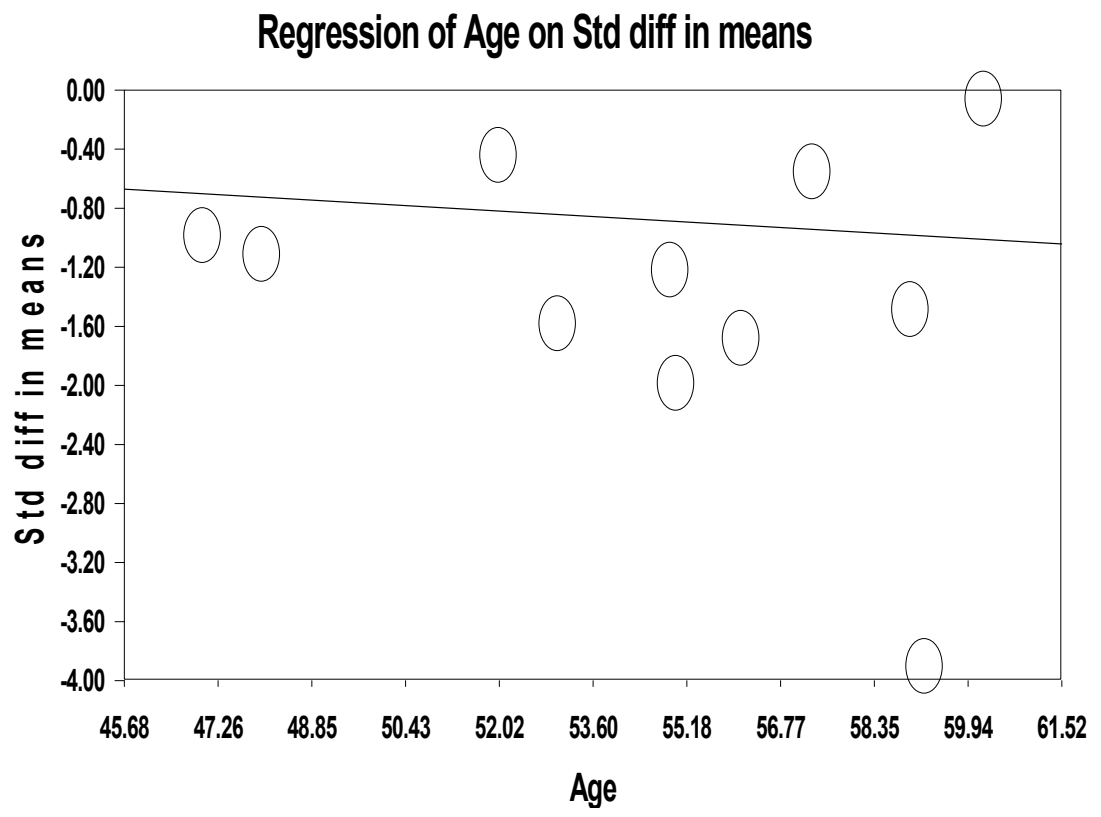

Graph 3. Meta-regression of the studies according to age:

This figure shows the relationship between age and the amount of LDL through Atorvastatin treatment. In the studies where the subjects are younger, the amount of LDL is higher and in those where the subjects are older, the amount of LDL is lower. 


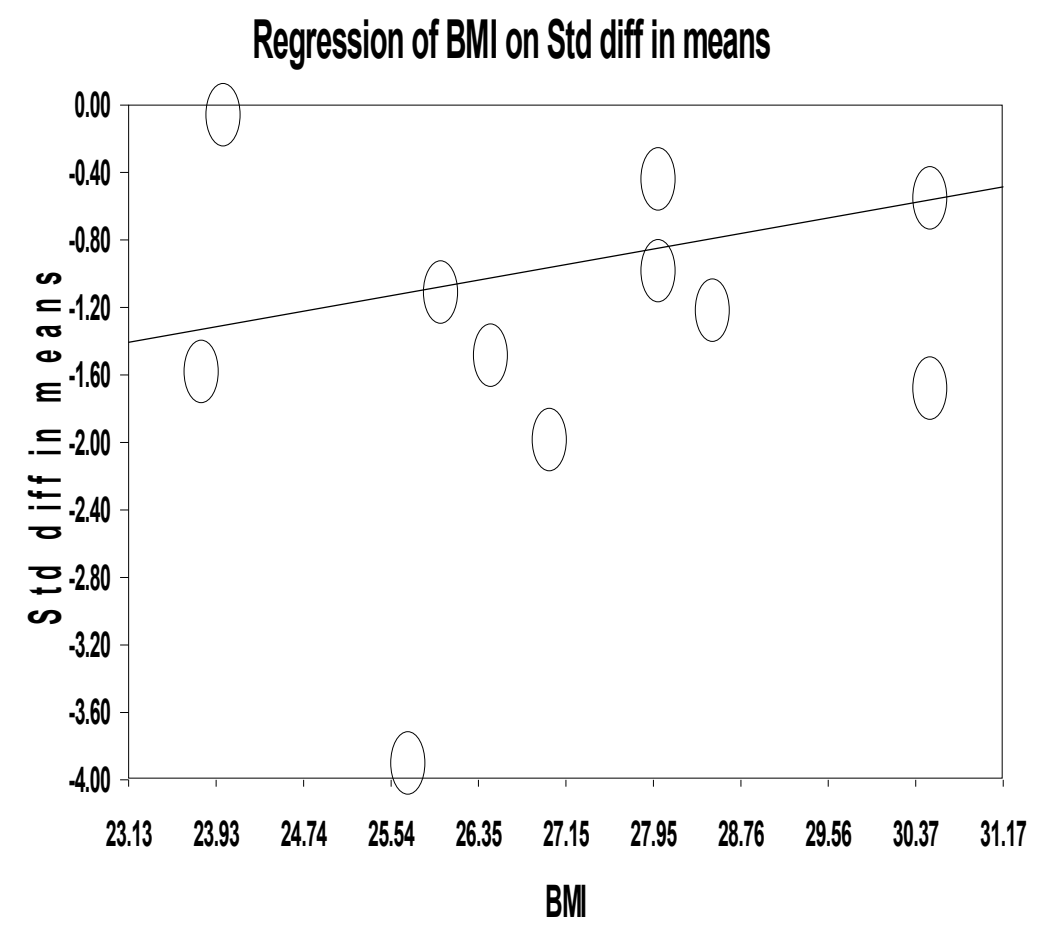

Graph 4. Meta-regression of the studies according to BMI and LDL reduction relationship through the use of Atorvastatin

This figure shows that in the individuals with higher BMI, LDL reduction is more and in subjects with lower BMI, LDL reduction is lower.

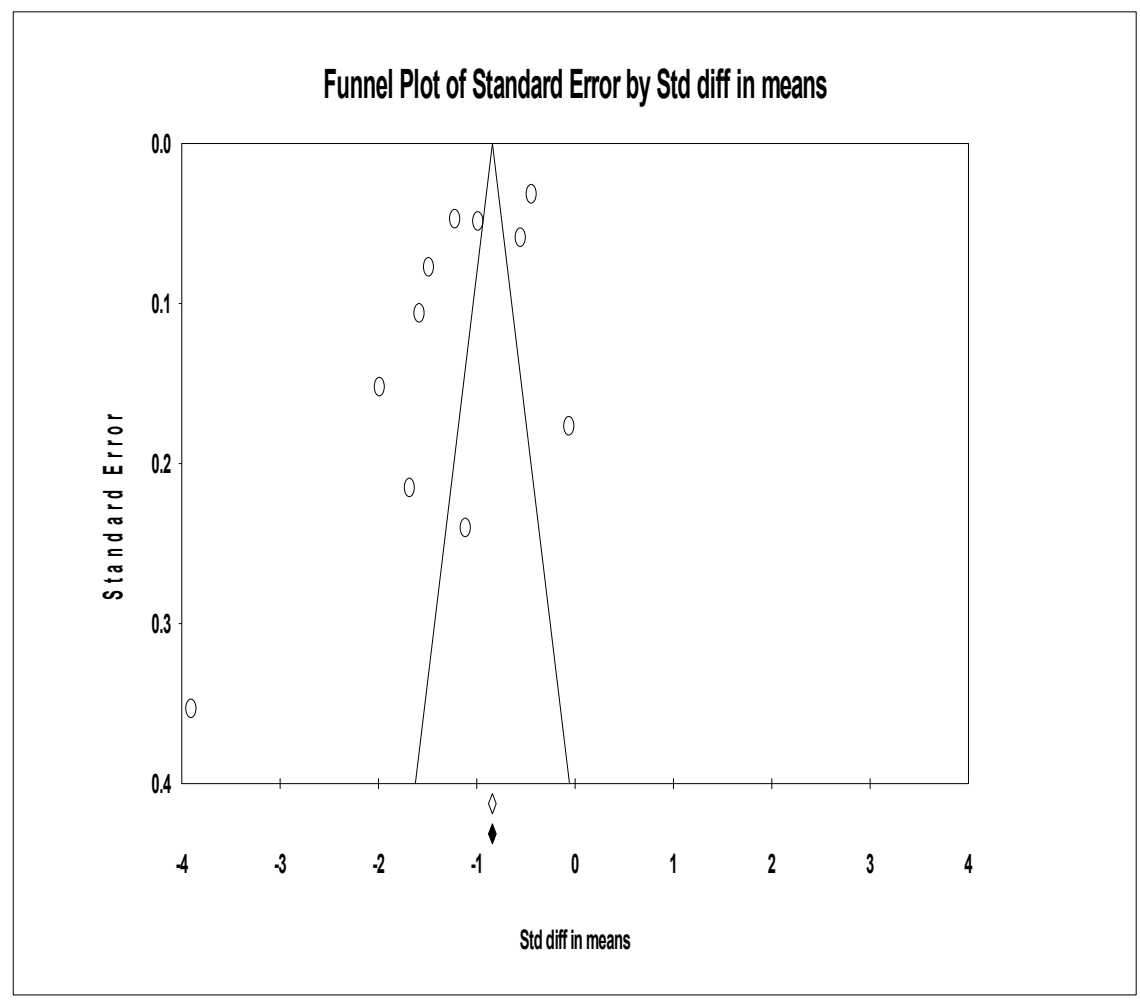

Graph 5. Publication bias of the articles according to Atorvastatin effect on LDL reduction 
Publication bias obtained through the results is shown in figure 5 and indicates that in this type of studies, bias has not had any effect and it is shown in the form of symmetry in a funnel-shaped graph. The sizes of the circles show the weights of the studies (greater circles have a higher number of samples and smaller ones have a lower number of samples).

\section{Discussion}

11 studies were conducted between 2003 and 2014. The total sample size was 3662 subjects with an average of 333 individuals in each study. The distribution of the studies in the world shows that six studies $(54.54 \%)$ were conducted in the Asian continent in the countries of South Korea, Japan and China, three studies (27.27\%) were performed in the European continent in the countries of Finland, Greece and Italy, one study (9.09\%) was carried out in the American continent and one (9.09\%) was conducted in the African continent.

According to the results of the study, the initial LDL reduction through Atorvastatin was 42.098 milligrams per Deciliter and the amount of LDL reduction after treatment by Atorvastatin was 33.23 milligrams per deciliter (Stalenhoef et al, 2005; Stein et al., 2003; Ferdinand et al., 2006; Hong et al., 2011; Saku et al., 2011; Qu et al., 2009; Brunetti et al., 2007).

The results of this study showed that the relationship between age and LDL reduction through Atorvastatin is significant. In studies where the ages of the people participating in the study was younger, the rate of LDL was high and in the studies where the ages of the people in the sample was older, the rate of LDL was lower. It can be said that LDL decreases more and faster in older people than younger ones and it can be controlled better. These results are consistent with the results of other studies (Park et al., 2010, Toyama et al., 2012, Liu et al., 2014 and Anagnostis et al., 2014).

According to the results of the study, the relationships between BMI and LDL reduction through Atorvastatin are significant. Thus, in subjects with higher BMI, LDL reduction is more and in subjects with lower BMI, LDL reduction is less. It can be concluded that Atorvastatin can reduce LDL faster in fat people compared to thin individuals. Other studies show similar results (Stalenhoef et al., 2005, Hong et al., 2011 and Park et al., 2010).

The results also show that the lowest amount of LDL reduction using Atorvastatin is 31.8 milligrams per deciliter (Ferdinand et al., 2006) and the highest rate of reduction by Atorvastatin is 82 milligrams per deciliter (Anagnostis et al., 2014). The average reduction by Atorvastatin is 33.33 milligrams per deciliter and this rate is consistent with the result of Keith's study and inconsistent with that of Anagnostis. Different statistical populations and different times at which the studies were conducted can be the reasons for this inconsistency.

Differences in the statistical population can be effective but differences in lifestyle or simultaneity of using different ways such as dieting and doing exercise might be the reason for such differences.

\section{Limitations of the Study}

The following can be some of the limitations of this study:

Most of the subjects in the sample were not selected randomly and this resulted in the selection of a sample of patients who were not representative of a population of patients with high blood fat. The variables studied were very few and limited so that in some studies different daily, weekly and monthly periods of treatment were reported but the precise amounts of LDL were not mentioned. In some studies, only other medicines were reported but the exact amounts before and after treatment were not reported. In some studies, comparisons regarding the subjects' sex or age were not carried out and data were provided generally. The total rate of LDL reduction through Atorvastatin was reported but comparison among different age groups was not done and individuals at risk were not recognized as belonging to different groups.

\section{Conclusion}

According to the results of the study Atorvastatin is a medicine in reducing LDL. It reduces the rate of LDL faster and to a larger extent. In addition, the amount of LDL reduction in the elderly and obese people takes place better and quicker that the young and thin individuals. The role of an inappropriate lifestyle such as eating fast food, immobility and lack of physical exercise must not be ignored.

\section{Acknowledgements}

Deputy of research and technology at Ilam University of medical sciences

\section{Competing Interests Statement}

The authors declare that there is no conflict of interests regarding the publication of this paper. 


\section{References}

Anagnostis, P., Adamidou, F., Slavakis, A., Polyzos, S. A., Selalmatzidou, D., Panagiotou, A., ... Kita, M. (2014). Comparative effect of atorvastatin and rosuvastatin on 25-hydroxy-vitamin D levels in non-diabetic patients with dyslipidaemia: a prospective randomized open-label pilot study. Open Cardiovasc Med J, 8, 55-60. http://dx.doi.org/10.2174/1874192401408010055

Anagnostis, P., Selalmatzidou, D., Polyzos, S. A., Panagiotou, A., Slavakis, A., Panagiotidou, A., ... Kita, M. (2011). Comparative effects off rosuvastatin and atorvastatin on glucose metabolism and adipokine levels in non-diabetic patients with dyslipidaemia: a prospective randomised open - label study. International journal of clinical practice, 65(6), 679-683. http://dx.doi.org/10.1111/j.1742-1241.2011.02655.x

Begg, C. B., \& Mazumdar, M. (1994). Operating characteristics of a rank correlation test for publication bias. Biometrics, 1088-1101. http://dx.doi.org/10.2307/2533446

Brunetti, N. D., Maulucci, G., Casavecchia, G. P., Distaso, C., De Gennaro, L. U. I. S. A., Luigi Pellegrino, P. I. E. R., \& Di Biase, M. A. T. T. E. O. (2007). Improvement in endothelium dysfunction in diabetics treated with statins: a randomized comparison of atorvastatin $20 \mathrm{mg}$ versus rosuvastatin $10 \mathrm{mg}$. Journal of interventional cardiology, 20(6), 481-487. http://dx.doi.org/10.1111/j.1540-8183.2007.00293.x

Brunetti, N. D., Maulucci, G., Casavecchia, G. P., Distaso, C., De Gennaro, L. U. I. S. A., Luigi Pellegrino, P. I. E. R., \& Di Biase, M. A. T. T. E. O. (2007). Improvement in endothelium dysfunction in diabetics treated with statins: a randomized comparison of atorvastatin $20 \mathrm{mg}$ versus rosuvastatin $10 \mathrm{mg}$. Journal of interventional cardiology, 20(6), 481-487.

Cochrane Collaboration. (2008). Chapter 7: selecting studies and collecting data. In J. P. Higgins, \& S. Green, Cochrane handbook for systematic reviews of interventions version, 5(0). Retrieved from www.cochrane-handbook.org

Egger, M., Smith, G. D., Schneider, M., \& Minder, C. (1997). Bias in meta-analysis detected by a simple, graphical test. Bmj, 315(7109), 629-634. http://dx.doi.org/10.1136/bmj.315.7109.629

Emerging Risk Factors Collaboration. (2010). C-reactive protein concentration and risk of coronary heart disease, stroke, and mortality: an individual participant meta-analysis. The Lancet, 375(9709), 132-140. http://dx.doi.org/10.1016/S0140-6736(09)61717-7

Ferdinand, K. C., Clark, L. T., Watson, K. E., Neal, R. C., Brown, C. D., Kong, B. W., ... Yčas, J. (2006). Comparison of efficacy and safety of rosuvastatin versus atorvastatin in African-American patients in a six-week trial. The American journal of cardiology, 97(2), 229-235. http://dx.doi.org/10.1016/j.amjcard.2005.08.026

Genser, B., Grammer, T. B., Stojakovic, T., Siekmeier, R., \& Maerz, W. (2008). Effect of HMG CoA reductase inhibitors on low-density lipoprotein cholesterol and C-reactive protein: systematic review and meta-analysis. International journal of clinical pharmacology and therapeutics, 46(10), 497-510.

Hong, Y. J., Jeong, M. H., Hachinohe, D., Ahmed, K., Choi, Y. H., Cho, S. H., ... Sim, D. S. (2011). Comparison of effects of rosuvastatin and atorvastatin on plaque regression in Korean patients with untreated intermediate coronary stenosis. Circulation Journal, 75(2), 398-406. http://dx.doi.org/10.1253/circj.CJ-10-0658

Liu, Y., Liu, Y. H., Tan, N., Chen, J. Y., Zhou, Y. L., Li, L. W., ... \& Li, H. L. (2014). Comparison of the efficacy of rosuvastatin versus atorvastatin in preventing contrast induced nephropathy in patient with chronic kidney disease undergoing percutaneous coronary intervention. PloS one, 9(10), e111124. http://dx.doi.org/10.1371/journal.pone.0111124

Milionis, H. J., Rizos, E., Kostapanos, M., Filippatos, T. D., Gazi, I. F., Ganotakis, E. S., ... Elisaf, M. S. (2006). Treating to target patients with primary hyperlipidaemia: comparison of the effects of ATOrvastatin and ROSuvastatin (the ATOROS study). Current medical research and opinion, 22(6), 1123-1131. http://dx.doi.org/10.1185/030079906X112462

Park, J. S., Kim, Y. J., Choi, J. Y., Kim, Y. N., Hong, T. J., Kim, D. S., ... Seong, I. W. (2010). Comparative study of low doses of rosuvastatin and atorvastatin on lipid and glycemic control in patients with metabolic syndrome and hypercholesterolemia. The Korean journal of internal medicine, 25(1), 27-35. http://dx.doi.org/10.3904/kjim.2010.25.1.27

Qu, H. Y., Xiao, Y. W., Jiang, G. H., Wang, Z. Y., Zhang, Y., \& Zhang, M. (2009). Effect of atorvastatin versus rosuvastatin on levels of serum lipids, inflammatory markers and adiponectin in patients with 
hypercholesterolemia. Pharmaceutical research, 26(4), 958-964. http://dx.doi.org/10.1007/s11095008-9798-6

Saku, K., Zhang, B., \& Noda, K. (2011). Randomized head-to-head comparison of pitavastatin, atorvastatin, and rosuvastatin for safety and efficacy (quantity and quality of LDL)-The PATROL trial. Circulation Journal, 75(6), 1493-1505. http://dx.doi.org/10.1253/circj.CJ-10-1281

Stalenhoef, A. F., Ballantyne, C. M., Sarti, C., Murin, J., Tonstad, S., Rose, H., \& Wilpshaar, W. (2005). A comparative study with rosuvastatin in subjects with metabolic syndrome: results of the COMETS study. European heart journal, 26(24), 2664-2672. http://dx.doi.org/10.1093/eurheartj/ehi482

Stein, E. A., Strutt, K., Southworth, H., Diggle, P. J., Miller, E., \& HeFH Study Group. (2003). Comparison of rosuvastatin versus atorvastatin in patients with heterozygous familial hypercholesterolemia. The American journal of cardiology, 92(11), 1287-1293. http://dx.doi.org/10.1016/j.amjcard.2003.08.009

Toyama, K., Sugiyama, S., Oka, H., Iwasaki, Y., Sumida, H., Tanaka, T., ... Ogawa, H. (2012). Combination treatment of rosuvastatin or atorvastatin, with regular exercise improves arterial wall stiffness in patients with coronary artery disease. PloS one, 7(7), e41369. http://dx.doi.org/10.1371/journal.pone.0041369

\section{Copyrights}

Copyright for this article is retained by the author(s), with first publication rights granted to the journal.

This is an open-access article distributed under the terms and conditions of the Creative Commons Attribution license (http://creativecommons.org/licenses/by/4.0/). 